\title{
Measuring Undergraduate Students' Beliefs about and Career Interest in Bioproducts and Bioenergy
}

\author{
S. L. McAlexander, ${ }^{\mathrm{a}, \mathrm{b}, *}$ S. M. Noble, ${ }^{\mathrm{c}}$ K. McCance, ${ }^{\mathrm{a}}$ M. R. Blanchard, ${ }^{\mathrm{a}}$ and R. A. Venditti ${ }^{\mathrm{b}}$
}

Two survey instruments measuring undergraduate students' beliefs about bioproducts/bioenergy and related careers were developed and validated in this research study. The Beliefs about Bioproducts/Bioenergy (BABB) and Career Interest in Bioproducts/Bioenergy (CIBB) surveys were administered to undergraduate students enrolled in courses in a natural resources college. BABB $(N=168)$ and CIBB $(N=203)$ survey results were analyzed using exploratory factor analysis (EFA) and confirmatory factor analysis (CFA). Validity and reliability were demonstrated. The BABB has two related scales, Personal $(P)$ and Societal $(S)$, which can be used together or separately. ANOVA and t-test analyses determined that students with majors closely related to bioproducts/bioenergy held significantly more positive personal and societal beliefs about bioproducts/bioenergy, as well as related career interests. Differences were identified based on gender, but not by race/ethnicity. Measuring student beliefs about bioproducts/bioenergy and interest in related careers may help to gauge trends and changes in beliefs that influence environmentally-related choices and support efforts to prepare a diverse workforce for the bioeconomy. The authors recommend the use of these surveys to measure the impacts of academic and professional development experiences.

Keywords: Undergraduate; Bioeconomy; Bioproducts; Careers; Diverse workforce

Contact information: a: Department of STEM Education, North Carolina State University, 2310 Stinson Dr., Raleigh, NC 27695 USA; b: Department of Forest Biomaterials, North Carolina State University, 431

Dan Allen Drive, Raleigh NC 27695-8005 USA; c: Department of Psychology, North Carolina State

University, 2310 Stinson Dr., Raleigh, NC 27695 USA; *Corresponding author: slmcalex@ncsu.edu

\section{INTRODUCTION}

There is a global movement toward a bio-based economy to reduce reliance on fossil fuels and other non-renewable resources (Langholtz et al. 2016). This shift enables a reduction in greenhouse gas emissions, mitigation of climate change, and a contribution to energy independence (Guo and Song 2018). Bio-based products contributed $\$ 459$ billion (excluding biofuels) to the US economy in 2016, and jobs in these industries grew by $17 \%$ from 2014 to 2016 (Golden et al. 2018). Additionally, biofuels represent a major component of the bioeconomy-based sectors, with the ethanol industry alone providing 10 percent of US motor fuel (Mercier and Halbrook 2020). In the United States (US), social and economic norms, consumer education and preferences, current technologies, and the existing infrastructure need to be addressed to support the transition from a fossil fuelbased society to a renewable resource-based society (Smith and Diggans 2020). This transition requires wide-ranging and interdisciplinary knowledge and skills (Knierim et al. 2018) and the development of a competent workforce of science, technology, engineering, and mathematics (STEM) professionals (Sissine 2007). 
Many sectors of the STEM workforce currently lack the diverse perspectives of underrepresented minorities and females due, in part, to racial discrimination, sexism, and other structural barriers (National Science Foundation 2017, National Science Board 2019). Increasing the diversity of this workforce will help to provide new perspectives for innovation and sustainable solutions (Herring 2009). Growing the pool of skilled technical professionals overall, will help overcome current and predicted future STEM workforce shortfalls (NSB 2019).

The goal of this study is to develop validated surveys as tools to help the authors better understand student beliefs and career interest in bioproducts/bioenergy and to investigate how beliefs and interests for undergraduate students may differ by gender, race/ethnicity, and selected major. The surveys are offered to the greater community to evaluate the impacts of courses or other professional development experiences on student beliefs and career interest.

\section{Representation in Bioproducts and Bioenergy Fields}

According to US employment statistics, White men make up the majority of positions in bioproduct/bioenergy careers. Women are underrepresented in agriculture/ forestry/ hunting/fishing, wood product manufacturing, and biofuels production industries (Table 1). Black/African Americans have particularly low representation in the agriculture/forestry/hunting/fishing, wood products, paper manufacturing, and liquid biofuels industries (Table 1).

Table 1. Gender and Race/ethnicity Demographics for Select Bioproduct/ bioenergy Industries

\begin{tabular}{|l|c|c|c|c|c|c|}
\hline & $\begin{array}{c}\text { Total } \\
\text { Employed }\end{array}$ & Women & White & $\begin{array}{c}\text { Black / African } \\
\text { American }\end{array}$ & Asian & $\begin{array}{c}\text { Latinx/ } \\
\text { Hispanic }\end{array}$ \\
\hline US Workforce (age 16+) & $157,538,000$ & 47 & 77.7 & 12.3 & 6.5 & 17.6 \\
\hline $\begin{array}{l}\text { Agriculture, Forestry, Fishing, } \\
\text { and Hunting }\end{array}$ & $2,425,000$ & 26.2 & 93 & 2.2 & 1.7 & 27.5 \\
\hline $\begin{array}{l}\text { Paper Manufacturing and } \\
\text { Printing }\end{array}$ & 871,000 & 29.9 & 81.9 & 11.9 & 2.6 & 15 \\
\hline $\begin{array}{l}\text { Wood Products } \\
\text { Manufacturing }\end{array}$ & 466,000 & 20.9 & 86.2 & 8.1 & 1.1 & 19.9 \\
\hline Corn Ethanol Fuels & 34,866 & 30 & 82 & 6 & 6 & 9 \\
\hline $\begin{array}{l}\text { Woody Biomass Fuel for } \\
\text { Energy and Cellulosic Biofuel }\end{array}$ & 33,426 & 28 & 85 & 4 & 5 & 6 \\
\hline Biomass Electric Generation & 13,178 & 31 & 71 & 10 & 10 & 16 \\
\hline
\end{tabular}

Note. Race and ethnicity data are presented above. Those who identify with a Hispanic or Latino ethnicity may also identify as any race. Therefore, sums exceed $100 \%$.

aU.S. Bureau of Labor Statistics (2020a). ${ }^{b}$ National Association of State Energy Officials and Energy Futures Initiative (2020). 
Mirroring employment in forest-based sectors, the lack of representation of females and racial/ethnic minorities is also evident in college majors that lead to bioproduct/ bioenergy related careers (e.g., agriculture/natural resources; chemical, civil, industrial, materials, and mechanical engineering) (National Science Foundation 2020). Student experiences while pursuing STEM degrees can vary greatly based on socio-economic factors, geographic region, racial background, and gender, which then influence course persistence and future career pathways (Alegria and Branch 2015).

\section{Theoretical Framework}

This paper applies the Expectancy Value Theory of Achievement Motivation (EVT), a framework that posits that an individual's academic performance, persistence, and activity choices are most directly linked to their beliefs and the value they have for a task (task value) (Eccles and Wigfield 2002). EVT has been used to understand and predict individuals' motivations for achievement-related behavior choices, such as motivations underlying why students have sustained enrollment in STEM courses (Andersen and Ward 2014).

Task value has four major components: attainment value, intrinsic value, utility value, and cost. Attainment value is defined as the importance of doing well on a given task and is related to how well a certain choice fits with an individual's identity. For example, a student who identifies themselves as an environmentalist may be more likely to value learning about bioproducts/bioenergy. Intrinsic value is the enjoyment one anticipates gaining from performing the activity, such as a student who enjoys learning about bioenergy/bioenergy topics and/or believes in its inherent importance to society. Utility value or usefulness refers to how helpful a certain task is in reaching current and future goals, such as career objectives, whether the individual is or is not interested in the task for its own sake. For example, a student may learn about a sustainability topic due to professional goals or to fulfill a course requirement. Finally, cost is conceptualized as the perceived drawbacks of engaging in a task. For example, a student may consider learning about sustainability topics as important for their future (utility value), but express concerns about the time and effort that they will have to put into learning (cost).

\section{Research Questions}

The goal of this study was to develop valid and reliable instruments that would measure undergraduate students' beliefs about bioproducts and bioenergy (BABB) and career interests in bioproducts and bioenergy (CIBB), as well as underlying factors influencing differences in their beliefs and interests. The following questions guided this research:

1. Do the BABB and CIBB demonstrate evidence of validity and reliability in measuring undergraduate students' beliefs about and career interest for bioproducts/bioenergy?

2. What factors influence undergraduate students' beliefs about bioproducts/bioenergy?

3. What factors influence undergraduate students' interest in bioproducts/bioenergy related careers? 


\section{METHODS}

\section{Context and Participants}

Two new survey instruments were needed for a US Department of Agriculturefunded (USDA) project focused on diversifying participation in the US bioeconomy and quantifying the impacts of interventions. Administration and analysis procedures followed protocols approved by the university's Institutional Review Board. Several natural resources faculty members at a university in the southeastern US volunteered to invite students in their undergraduate courses to take the BABB and CIBB surveys. Faculty members shared Qualtrics survey links during in-person lectures or via learning management websites. All undergraduate students who were enrolled in the natural resources courses were eligible to participate, and all who participated did so voluntarily.

\section{Scale Development} (1998).

The surveys developed in this study were guided by methods identified by Hinkin

\section{Step 1: Item generation}

Items for the BABB and CIBB were sourced from the CLASS-Bio (Semsar et al. 2011) and SITS (Romine et al. 2014) and modified. Each item was reviewed for content validity by three faculty members and two graduate students serving as subject experts. The research team considered multiple terms as the focal concept of the surveys: bioeconomy, green economy, and circular economy. Eventually the group settled on Bioproducts/Bioenergy, although this construct is not a formalized discipline. The review team also provided suggestions regarding inclusion and exclusion of items, recommending that one instrument would focus on beliefs and the other on career interest. During informal follow-up interviews, three undergraduate students reviewed the items for clarity and time needed for completion.

$\mathrm{BABB}$. For the 34-item BABB, twenty-six items simply replaced the word "Biology" with "Bioproducts/Bioenergy" from the CLASS-Bio. Eight items on the BABB originated from the SITS because they were related to beliefs. The original SITS items assessed students" "ideas about biotechnology," and they were modified for inclusion in the BABB by replacing "Biotechnology" with "Bioproducts/Bioenergy." To ensure that students carefully read the survey items, a few BABB items were reverse-coded.

CIBB. Most of the CIBB's 18 items originated from the career-related items in the SITS. Ten SITS items remained unchanged, and six SITS items were slightly modified to include bioproduct/bioenergy-specific wording or to edit the wording in order to refer to general science instead of high school science. Two new bioproduct/bioenergy careerrelated items were created to address various types of bioproducts/bioenergy careers.

\section{Step 2: Questionnaire administration}

The BABB and CIBB instruments were administered to students via separate links to each online Qualtrics survey. Both surveys used a five-point Likert scale and asked students to indicate the extent to which they agreed or disagreed with each statement from Strongly Disagree (1) to Strongly Agree (5).

Students were asked to report their gender, race/ethnicity, major, and program year (Table 2). A few choices for majors were provided: Paper Science and Engineering (PSE), Sustainable Materials and Technology (SMT), Environmental Science (ENV), and Other 
Majors. Common write-ins for "other majors" included Animal Science, Business, Engineering (biomedical, chemical, electrical, and mechanical), Computer Science, and Education. Unfortunately, the number of students in each racial/ethnical group was not sufficient for statistical analysis. To allow for greater sample size, race/ethnicities groups were combined into Underrepresented Minorities (URM) and non-URM based on historical underrepresentation in STEM fields. For an in-depth discussion of the use of "URM" see Page et al. (2013). Students who self-identified as African American, Latino, Native American, and Multi-racial made up the URM group and students who selfidentified as White, non-Hispanic; Asian; and Indian made up the non-URM group. The authors realize that not all URM students (or non-URM students) have parallel experiences and that intersectional identities, including but not limited to age, gender, race/ethnicity, sexuality, and disability, are vast and complicated and are not fully addressed by this study.

Table 2. Self-reported Student Demographic Data for the BABB and CIBB and for all Undergraduates in the College of Natural Resources (CNR)

\begin{tabular}{|l|l|c|c|c|}
\hline \multirow{2}{*}{ Demographics } & $\begin{array}{c}\text { Undergraduate } \\
\text { Population } \\
(2019)^{\mathrm{a}}\end{array}$ & $\begin{array}{c}\text { BABB } \\
(N=168)\end{array}$ & $\begin{array}{c}\text { CIBB } \\
(N=203)\end{array}$ \\
\hline Gender & Female & $37.3 \%$ & $48.2 \%$ & $54.2 \%$ \\
\hline & Male & $62.7 \%$ & $50.6 \%$ & $44.8 \%$ \\
\hline & Other/No Response & $0.0 \%$ & $1.2 \%$ & $0.0 \%$ \\
\hline Race/ethnicity & White & $75.9 \%$ & $74.4 \%$ & $75.4 \%$ \\
\hline & Asian & $3.2 \%$ & $8.9 \%$ & $9.9 \%$ \\
\hline & Black/African American & $5.2 \%$ & $4.8 \%$ & $4.9 \%$ \\
\hline & Latino & $5.1 \%$ & $4.2 \%$ & $3.4 \%$ \\
\hline & Multi-racial (two or more) & $3.8 \%$ & $4.2 \%$ & $3.0 \%$ \\
\hline & Native American & $\mathrm{N} / \mathrm{A}$ & $1.8 \%$ & $1.5 \%$ \\
\hline & Indian & $\mathrm{N} / \mathrm{A}$ & $1.2 \%$ & $1.0 \%$ \\
\hline & No response/unknown & $4.0 \%$ & $0.6 \%$ & $1.0 \%$ \\
\hline & International (CNR use only) & $2.0 \%$ & - & - \\
\hline & $\begin{array}{l}\text { Underrepresented Minority } \\
\text { (URM) status }\end{array}$ & $14.1 \%$ & $14.9 \%$ & $12.3 \%$ \\
\hline & $\begin{array}{l}\text { Paper Science and Engineering } \\
\text { (PSE) }\end{array}$ & - & $41.7 \%$ & $38.9 \%$ \\
\hline & $\begin{array}{l}\text { Sustainable Materials and } \\
\text { Majors }\end{array}$ & - & $6.0 \%$ & $6.9 \%$ \\
\hline & Environmental Science (ENV) & - & $28.6 \%$ & $30.0 \%$ \\
\hline & Other majors & $23.8 \%$ & $24.1 \%$ \\
\hline
\end{tabular}

Note. ${ }^{a}$ College of Natural Resources (2020). 


\section{Step 3: Initial item reduction}

Once the surveys were administered and data had been collected, exploratory factor analysis using SPSS software (IBM 2019) was used to determine the number of factors that best explain the latent variables of interest. The dataset was cleaned by deleting responses that failed to complete the survey entirely, incorrectly responded to an instructed response item, or answered all or most all questions with the same score (Meade and Craig 2012; Johnson 2005). The cleaning procedure led to the removal of 61 responses, resulting in $(N$ $=168$ ) for BABB and 20 responses for CIBB, resulting in $(N=203)$. Each dataset was halved into two subsamples: one for the EFA and the other for the CFA. A principal axis factoring procedure was performed using an oblique Promax rotation. Factor loadings were based on Kaiser criterion (eigenvalues greater than 1) and a scree test for percentage of variance explained was generated (Cattell 1966; Preacher and MacCallum 2003). Items with a covariance greater than 0.40 were sorted into factors (Ford et al. 1986).

$B A B B$. Initial analyses by principal axis factoring $(n=84)$ indicated the presence of three loadings. Factors two and three appeared to be tapping into individual's learning and study habits rather than beliefs about bioproducts/bioenergy itself. Thus, these items were removed from future analyses. The remaining 17-item first factor accounted for $21.4 \%$ of the variance in the items and had an acceptable internal reliability (Cronbach's $\alpha$ $=.88$; Nunnally 1978).

$C I B B$. Initial analyses by principal axis factoring $(n=101)$ indicated the presence of three factors. Factor one was found relevant to the study of career interest in bioproducts/bioenergy, whereas factors two and three regarding the usefulness of technology and science interest were less relevant to the research focus. The "Career Interest in Bioproducts/Bioenergy" factor (8-items) accounted for $27.1 \%$ of the variance and showed sufficient internal reliability (Cronbach's $\alpha=.87$ ). Three items within the factor referenced more generic careers ('science' or 'scientist') instead of bioproducts/bioenergy careers and removing them resulted in a slightly improved internal reliability of the measure $(\alpha=.91)$.

\section{Step 4: Confirmatory Factor Analysis}

$B A B B$. To conduct the CFA the remaining half of the sample $(n=84)$ was used. Using SPSS Amos, a CFA for a single factor loading of the 17 items was conducted. The chi-square test result for the 17 item model indicated a poor fit $(\chi 2=206.53, \mathrm{df}=119, \mathrm{p}<$ .001; McIver and Carmines 1981; Hinkin 1998). The results of goodness of fit analyses also indicated unsatisfactory model fit $(\mathrm{CFI}=.80, \mathrm{RMSEA}=.09, \mathrm{SRMR}=.09 ; \mathrm{Hu}$ and Bentler 1999).

Seeking a better-fit model, items were reexamined for theory-based patterns. Guided by EVT motivational constructs, a relationship between the items and task values was observed with each task value demonstrating either a personal (9-items) or societal (8items) orientation. The BABB-Personal (BABB-P) items related to one's personal relationship with bioproducts/bioenergy, whereas the BABB-Societal (BABB-S) items related to beliefs about bioproducts/bioenergy in society. Factor loading, by SPSS Amos supported the two subscales (Fig. 1). The intercorrelated model indicated an improved fit $(\chi 2=156.59$, df $=118, \mathrm{p}=.10)$. Additionally, results of goodness of fit indices were acceptable for the model $(\mathrm{CFI}=.91, \mathrm{RMSEA}=.06, \mathrm{SRMR}=.08)$ and internal reliability by Cronbach's alpha was sufficient (BABB-P, $\alpha=.86$; BABB-S, $\alpha=.81$ ).

$C I B B$. The CFA was conducted for a single factor loading of the five items. The chi-square test result for the five item model indicated poor fit $(\chi 2=18.98, \mathrm{df}=5, \mathrm{p}<.01)$. 
The results of the goodness of fit indices analyses also indicated poor model fit. While CFI and SRMR indicated satisfactory model fit, RMSEA did not $(\mathrm{CFI}=.95$, RMSEA $=.17$, SRMR = .04). By removing the item with a poor t-value, the resulting four item model (Fig. 1) had improved performance $(\chi 2=2.40$, df $=2, \mathrm{p}=.302)$. Additionally, results of goodness of fit indices were improved for the model $(\mathrm{CFI}=.998, \mathrm{RMSEA}=.04, \mathrm{SRMR}=$ $.02)$, and internal reliability by Cronbach's alpha was sufficient $(\alpha=.86)$.
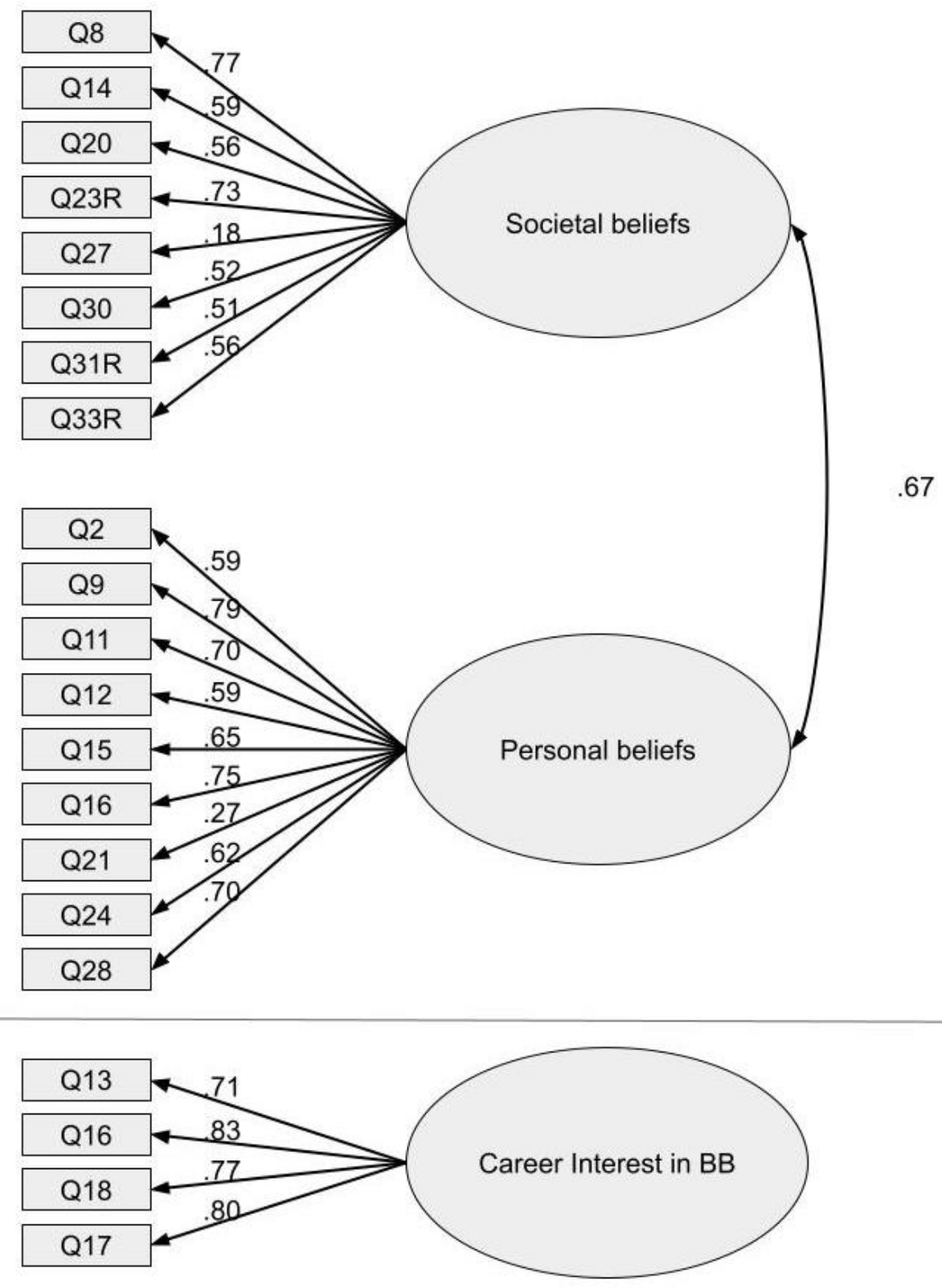

Fig. 1. SPSS Amos output for 9-item factor for BABB-P, 8-item BABB-S, and 4-item CIBB. Ovals represent latent variables. Causal effects are represented by single-headed arrows and covariance is represented by the two-headed arrow. 


\section{Final Survey Items}

Beliefs about bioproducts/bioenergy - personal (BABB-P)

1. I enjoy explaining Bioproducts/Bioenergy concepts that I learn about to my friends.

2. I want to study about Bioproducts/Bioenergy because I want to make a contribution to society.

3. I enjoy figuring out answers to questions about Bioproducts/Bioenergy.

4. It is a valuable use of my time to study the fundamental experiments behind Bioproducts/Bioenergy concepts.

5. If I had plenty of time, I would learn about Bioproducts/ Bioenergy outside of class.

6. Learning about Bioproducts/Bioenergy changes my ideas about how the world works.

7. When I am not pressed for time, I will continue to work on a Bioproducts/Bioenergy problem until I understand why something works the way it does.

8. I think about the Bioproducts/Bioenergy that I encounter in everyday life.

9. When learning about Bioproducts/Bioenergy, I relate the important information to what I already know rather than just memorizing it the way it is presented.

\section{Beliefs about bioproducts/bioenergy- societal (BABB-S)}

1. Bioproducts/Bioenergy help create solutions to the world's problems.

2. Bioproducts/Bioenergy help maintain a healthy environment.

3. Bioproducts/Bioenergy are useful for solving the problems of everyday life.

4. Bioproducts/Bioenergy contribute to the social, environmental, and economic success of the United States.

5. Bioproducts/Bioenergy are not important for modern life. (Reverse coded)

6. Mathematical skills are important for understanding Bioproducts/Bioenergy concepts.

7. Bioproducts/Bioenergy concepts are just to be memorized.

8. Bioproducts/Bioenergy do not contribute to the social, environmental, and economic success of North Carolina. (Reverse coded)

Career interest in bioproducts/bioenergy (CIBB)

1. I would like to work with people who make discoveries in bioproducts/bioenergy.

2. I would enjoy working in a bioproducts/bioenergy laboratory.

3. I would enjoy working in a research setting to develop new bioproducts/bioenergies.

4. I would like to work in a biorefinery (a production site for bioproducts/bioenergy). 


\section{RESULTS \& DISCUSSION}

\section{BABB Demographic Analysis}

Mean scores were normally distributed

BABB-P and the BABB-S were normally distributed for demographic variables based on skewness and kurtosis according to Huck's (1974) guidance of acceptable ranges of an absolute value less than one.

No difference was found by gender or URM status

Mean scores were compared across gender, URM status, and major. Using independent t-tests, no statistically significant differences were found by gender or URM status for BABB-P or BABB-S.

Bioproducts-related majors have more positive personal and societal beliefs

BABB scores were high across all majors for both BABB-P $(M=3.70, S D=.60)$ and the BABB-S $(M=4.23, S D=.45)$. To assess differences across majors for BABB-P and BABB-S ANOVAs were followed by post-hoc Tukey's HSD tests. For BABB-P, there was a significant main effect by major $(\mathrm{F}(3,164)=14.13, p<.001)$; PSE and SMT majors reported higher scores than ENV and other majors (Fig. 2). For BABB-S, there was also a significant main effect by major $(\mathrm{F}(3,164)=8.03, p<.001)$; SMT, PSE, and ENV majors reported higher scores than other majors (Fig. 2).
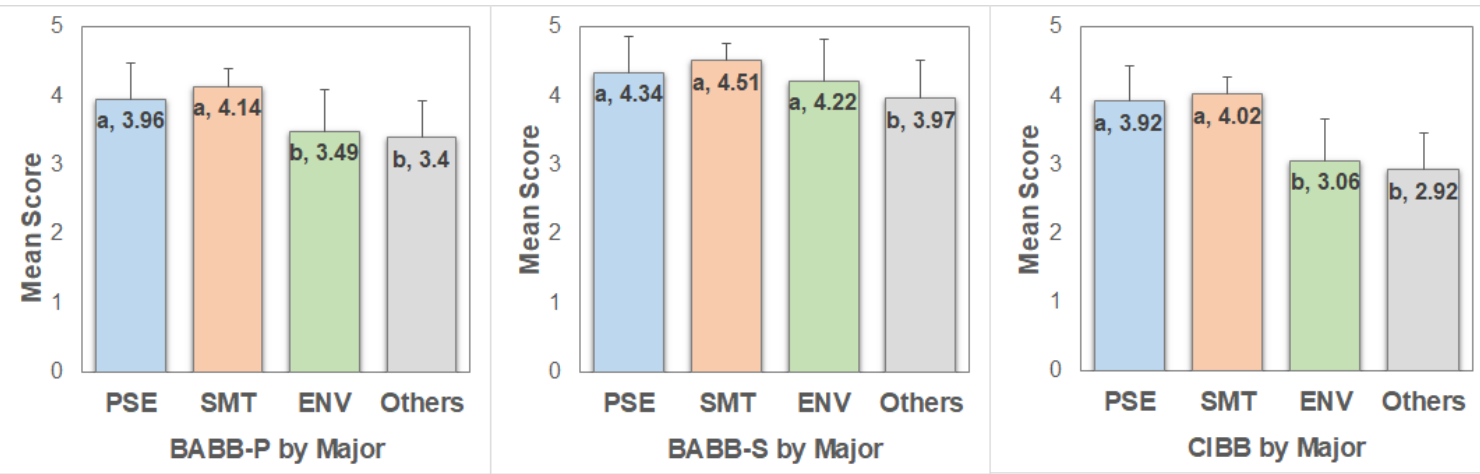

Fig. 2. Comparisons of majors for BABB-P, BABB-S, CIBB means by ANOVA Note. Paper Science and Engineering (PSE), Sustainable Materials and Technology (SMT), Environmental Science (ENV), and Other Majors. Bars represent one standard deviation in the positive direction. Majors sharing a letter are not significantly different $(a=0.05)$.

Students across majors saw the value of bioproducts/bioenergy to society

One-way ANOVAs followed by post-hoc Tukey's HSD test revealed differences between majors for specific BABB-P and BABB-S items. Most items revealed the same pattern as the overall factor, with SMT and PSE majors expressing more positive beliefs for each item than their ENV and Other Major peers. Interestingly, there was no significant difference across majors for BABB-S Q5 "Bioproducts/Bioenergy are not important for modern life (reverse-coded)" $(M=4.36, S D=0.78)$ and BABB-S Q8 "Bioproducts/ Bioenergy do not contribute to the social, environmental, and economic success of the North Carolina (reverse-coded)" $(M=4.23, S D=0.91)$. Strong beliefs for these two items across majors indicated that students saw a high utility value for bioproducts/bioenergy in modern society and at the state level. 


\section{CIBB Demographic Analysis}

Mean scores were normally distributed

CIBB factor scores were determined to be normal, with a range from 1.00 to 5.00 $(M=3.42)$, tests of skewness and kurtosis were normal $(-.47$ and .01$)$.

Males had greater interest in bioproduct/bioenergy careers; No differences in interest were found by URM status

For the single CIBB factor, a mean score of four items, males reported significantly $(\mathrm{p}=0.012)$ higher beliefs about bioproducts/bioenergy $(M=3.57, S D=.83)$ compared to females $(M=3.25, S D=.93)$. However, two-factor ANOVA found no statistically significant gender differences within each major. Further, there were no significant differences between non-URM students and URM students.

Bioproducts-related majors had greater interest in bioproducts/bioenergy careers

Across majors, there was a significant main effect for the CIBB factor $(\mathrm{F}(3,199)$ $=14.81, p<.001)$; PSE majors and SMT majors had more positive beliefs about careers in bioproducts and bioenergy than either ENV majors or other majors (Fig. 1).

Overall, interest was high; males were more interested in working in laboratory and biorefinery settings

In additional t-tests of all majors, males expressed significantly more interest in working in a bioproducts/bioenergy laboratory (Males: $M=4.48, S D=1.03$; Females: $\mathrm{M}=$ $3.09, S D=1.00 ; p=0.007$ ) and working in a biorefinery (Males: $M=3.45, S D=1.04$; Females: $M=3.03, S D=1.16 ; p=0.008)$. Males and females expressed high interest levels for working with people who make discoveries in bioproducts/bioenergy (Q1) and in working in bioproducts/bioenergy research settings (Q3). Within each of the major groups (PSE \& SMT combined for 2-factor ANOVA), no significant differences in career interest were found by gender.

\section{Validity and Reliability of BABB and CIBB in Measuring Undergraduate Students' Beliefs and Career Interest}

Nine items that measure personal beliefs and eight items that measure societal beliefs about bioproducts and bioenergy were validated with undergraduate students. Additionally, the BABB was able to discern differences in the undergraduates' views by major. No differences were found by URM status, although the choice to combine race/ethnic groups, due to low numbers, is a persistent issue with conducting some of these studies in the sciences (e.g., Blanchard and Wheeler 2019). In contrast to previous findings with the CLASS-BIO (Semsar et al. 2011), the smaller number of items selected performed as a single latent factor and the items developed for the BABB operated at both a personal and societal level, in two related scales.

Four items that measure interest in bioproducts/bioenergy careers were validated with undergraduate students. The CIBB survey was able to discern between career interests based on gender, and major. No differences were detected between URM and non-URM students, perhaps due to the low sample. 


\section{Factors that Influence Undergraduate Students' Beliefs}

Undergraduate students' beliefs about bioproducts/bioenergy were positive, with $54 \%$ BABB factor agreement with experts, consistent with the CLASS-Bio, which has revealed 56 to $78 \%$ undergraduate student agreement with expert views (Semsar et al. 2011; Ding and Mollohan 2015; Jeffery et al. 2016; Beumer 2019). The students enrolled in the natural resources courses in the study were aware of and saw value in bioproducts and bioenergy. Societal beliefs were scored higher than personal beliefs, which may relate to how students see their own roles when it comes to sustainability.

No differences by gender were observed, which is consistent with previous findings of the CLASS-Bio (Jeffery et al. 2016), but contrasts with multiple CLASS-Physics results, which found higher scores for males than females (Adams et al. 2006; Wheeler and Blanchard 2019). Identifying strong beliefs about bioproducts/bioenergy and related career interest suggests the potential to engage all students in learning about and promoting bioproducts/bioenergy.

$B A B B-S$. Societal beliefs about bioproducts/bioenergy differed by major. Students in PSE, SMT, and ENV majors all held significantly higher societal beliefs compared to those in other majors. These results match the expectation that students who have selected majors related to the environment and sustainability would value the benefit of bioproducts and bioenergy to society. These findings are consistent with Semsar's (2011) work indicating that biology majors have higher scores (72\% agreement) than non-majors (57\% agreement). There were two items from BABB-S that remained high across majors, indicating that students held a high utility value for bioproducts/bioenergy in modern society and at the state level.

$B A B B-P$. PSE and SMT, which are two majors that both focus on the use of biomaterials, had high personal beliefs about bioproducts and bioenergy. Students in these majors are likely to be more familiar with the utility of bioproducts and bioenergy. Data were collected at only one point in time, so students' beliefs may have changed over time and may result from various influences. Students may have selected their major based on pre-existing values about bioproducts/bioenergy and sustainability and/or they developed these beliefs during their coursework.

Additionally, the survey makes a theoretical contribution to the field, as the personal belief items relate to motivational constructs in the Expectancy Value Theory of Achievement Motivation: beliefs related to intrinsic, attainment, and utility task values (Eccles and Wigfield 2002). The societal beliefs are primarily related to utility task value, relating to students' perceptions of the usefulness of bioproducts and bioenergy to society.

\section{Factors that Influence Students' Interest in Careers}

Although the number of URM students in this study was relatively low, there were no observable differences in career interest determined between URM and non-URM groups. Therefore, the authors see potential in recruiting students from historically underrepresented race/ethnicities to careers in bioproducts/bioenergy. Although differences in career interest were identified by gender, overall, when comparing males and females within the same major, there were no significant differences. PSE and SMT, both majors that focus on forest biomaterials, had more positive interest in related careers than other majors. When males and females within PSE and SMT were compared, there was no difference in their interest to work with bioproducts/bioenergy. These findings make a contribution to the field, as previous investigations into career interest, such as the SITS, 
have not reported demographics based on gender, race/ethnicity, or URM status (e.g., Romine et al. 2014).

\section{Limitations}

The present findings should be viewed in light of several limitations. The number of participants was relatively small, located at one research university, and was selfreported at one point in time. The generalizability of our findings, therefore, may be limited to the population in the current study. The authors focused on motivation as described within Expectancy Value Theory, and did not necessarily take other career theories into account as factors influencing student beliefs or interest.

\section{CONCLUSIONS}

This study established the validity and reliability of the Beliefs about Bioproducts/Bioenergy (BABB) with two types of items (Personal and Societal) and the Career Interest in Bioproducts/Bioenergy (CIBB) with undergraduate students. Differences in beliefs and career interest were observed to vary across demographic factors within an undergraduate population at one university in the southeastern US. Given the experiences in developing these surveys and in administering them, the following conclusions are offered:

1. The BABB-P and BABB-S can be used to measure students' beliefs about bioproducts and bioenergy - one at a personal level and one at a more societal level. These items may be administered together or separately depending on the inclusion criteria of the researchers.

2. The CIBB survey measured career interest for bioproducts and bioenergy.

3. The surveys were able to discern differences by gender and major.

4. Undergraduate students in bioproduct/bioenergy related majors held more positive beliefs about bioproducts and bioenergy than those in less closely related majors, although overall interest was high.

5. There were no differences by gender or URM status in students' beliefs about bioproducts and bioenergy.

6. Overall, gender differences were noted in career interest with males more interested in careers in laboratory and biorefining settings. However, there were no gender differences found within majors.

Given these conclusions, the use of these surveys is recommended for pre and post intervention to measure impacts on undergraduate students' bioproducts/bioenergy beliefs and career interests, similar to the approach used with the SITS (Romine and Sadler 2016). Interventions could include a bioproducts or bioenergy internship, or other experiences in environmental science, sustainability, or forest bioproducts type coursework, laboratory work, or related experiences. These measures may be useful for: establishing a baseline of beliefs for a certain group; examining changes due to a course, program, or other intervention; or comparing beliefs between demographic groups. Especially for those who 
are looking to ground their work in constructs that are more theoretically driven, the BABB scales, both Personal and Societal, will provide that grounding. The authors expect that these surveys will help others to support and measure efforts to increase and further diversify the students who are majoring in related fields and considering careers in bioproducts and bioenergy.

\section{ACKNOWLEDGMENTS}

This research was supported by the USDA AFRI Competitive Grants Program: Sustainable Bioenergy and Bioproducts Challenge Area: Investing in America's Scientific Corps: Preparing a New Generation of Students, Faculty, and Workforce for Emerging Challenges in Bioenergy, Bioproducts, and the Bioeconomy, award number: 2017-6700926771, Program Code - A6131. Thanks to Adam Scouse for his assistance with the literature review. An extended version of this paper is available in dissertation format (McAlexander 2021).

\section{REFERENCES CITED}

Adams, W. K., Perkins, K. K., Podolefsky, N. S., Dubson, M., Finkelstein, N. D., and Wieman, C. E. (2006). "New instrument for measuring student beliefs about physics and learning physics: The Colorado Learning Attitudes about Science Survey," Physical Review Special Topics - Physics Education Research 2(1). DOI:

10.1103/physrevstper.2.010101

Alegria, S. N., and Branch, E. H. (2015). "Causes and consequences of inequality in the STEM: Diversity and its discontents," International Journal of Gender, Science and Technology 7(3), 321-342.

Andersen, L., and Ward, T. J. (2014). "Expectancy-value models for the STEM persistence plans of ninth-grade, high-ability students: A comparison between Black, Hispanic, and White students," Science Education 98(2), 216-242. DOI: $10.1002 /$ sce. 21092

Beumer, A. (2019). "Student attitudes towards biology in an introductory biology course at a two-year, open access college," The Journal for Research and Practice in College Teaching 4(1), 40-54.

Cattell, R. B. (1966). "The scree test for the number of factors," Multivariate Behavioral Research 1(2), 245-276. DOI: 10.1207/s15327906mbr0102_10

Ding, L., and Mollohan, K. N. (2015). "How college-level introductory instruction can impact student epistemological beliefs," Journal of College Science Teaching 44(4), 19-27. DOI: $10.2505 / 4 /$ jcst15_044_04_19

Eccles, J. S., and Wigfield, A. (2002). "Motivational beliefs, values, and goals," Annual Review of Psychology 53(1), 109-132. DOI:

10.1146/annurev.psych.53.100901.135153

Ford, J. K., MacCallum, R. C., and Tait, M. (1986). "The application of exploratory factor analysis in applied psychology: A critical review and analysis," Personnel Psychology 39(2), 291-314. DOI: 10.1111/j.1744-6570.1986.tb00583.x

Golden, J. S., Handfield, R. B., Daystar, J. S., and McConnell, T. E. (2018). An Economic Impact Analysis of the U.S. Biobased Products Industry: A Report to the Congress of 
the United States of America Update. A Joint Publication of the Duke Center for Sustainability \& Commerce and the Supply Chain Resource Cooperative at North Carolina State University.

Guo, M., and Song, W. (2018). "The growing US bioeconomy: Drivers, development and constraints," New Biotechnology 49, 48-57. DOI: 10.1016/j.nbt.2018.08.005

Herring, C. (2009). "Does diversity pay?: Race, gender, and the business case for diversity," American Sociological Review 74(2), 208-224. DOI: 10.1177/000312240907400203

Hinkin, T. R. (1998). "A brief tutorial on the development of measures for use in survey questionnaires," Organizational Research Methods 1(1), 104-121. DOI: 10.1177/109442819800100106

Hu, L. T., and Bentler, P. M. (1999). "Cutoff criteria for fit indexes in covariance structure analysis: Conventional criteria versus new alternatives," Structural Equation Modeling: A Multidisciplinary Journal 6(1), 1-55. DOI:10.1080/10705519909540118

Huck, S. W., Cormier, W. H., and Bounds, W. G. (1974). Reading Statistics and Research. Harper \& Row.

Jeffery, E., Nomme, K., Deane, T., Pollock, C., and Birol, G. (2016). "Investigating the role of an inquiry-based biology lab course on student attitudes and views toward science," CBE Life Sciences Education 15(4). DOI: 10.1187/cbe.14-11-0203

Johnson, J. A. (2005). "Ascertaining the validity of individual protocols from web-based personality inventories," Journal of Research in Personality 39(1), 103-129. DOI: 10.1016/j.jrp.2004.09.009

Knierim, A., Laschewski, L., and Boyarintseva, O. (2018). "Inter-and transdisciplinarity in bioeconomy," in: Bioeconomy, I. Lewandowski (ed.), Springer, pp. 39-72. DOI: 10.1007/978-3-319-68152-8_4

Langholtz, M. H., Stokes, B. J., Eaton, L. M., Brandt, C. C., Davis, M. R., Theiss, T. J., Turhollow Jr, A. F., Webb, E., Coleman, A., Wigmosta, M., and Efroymson, R. A. (2016). 2016 Billion-Ton Report: Advancing Domestic Resources for a Thriving Bioeconomy, Volume 1: Economic Availability of Feedstocks. ORNL/TM-2016/160. Oak Ridge National Laboratory, Oak Ridge, TN. DOI: 10.2172/1271651

McAlexander, S. L. (2021). Investigating Undergraduate Career Development Experiences to Support Historically Underrepresented Science and Engineering Students. Doctoral Dissertation, North Carolina State University. https://repository.lib.ncsu.edu/bitstream/handle/1840.20/38695/etd.pdf?sequence=1

McIver, J., and Carmines, E. G. (1981). Unidimensional Scaling (No. 24). Sage. DOI: 10.4135/9781412986441

Meade, A. W., and Craig, S. B. (2012). "Identifying careless responses in survey data," Psychological Methods 17(3), 437-455. DOI: 10.1037/a0028085

Mercier, S. A., and Halbrook, S. A. (2020). "Policy spotlight: Federal Biofuels Policy," in: Agriculture Policy of the United States. Palgrave Studies in Agricultural Economics and Food Policy, Palgrave Macmillan, pp. 377-387. DOI: 10.1007/978-3030-36452-6_22

National Association of State Energy Officials and Energy Futures Initiative. (2020). 2020 U.S. Energy \& Employment Report. Available at https://static1.squarespace.com/static/5a98cf80ec4eb7c5cd928c61/t/5ee78423c6fcc20 e01b83896/1592230956175/USEER+2020+0615.pdf

National Science Foundation, National Center for Science and Engineering Statistics. (2017). Women, Minorities, and Persons with Disabilities in Science and 
Engineering: 2017. Special Report NSF 17-310. Arlington, VA. Available at www.nsf.gov/statistics/wmpd/.

National Science Board (NSB). (2019). The Skilled Technical Workforce: Crafting America's Science \& Engineering Enterprise. Special Report NSF NSB-2019-23. Available at https://www.nsf.gov/nsb/publications/2019/nsb201923.pdf

National Science Foundation, National Center for Science and Engineering Statistics. (2020). "Science and Engineering Degrees, by Race and Ethnicity of Recipients." Available at https://ncsesdata.nsf.gov/sere/2018/, accessed 5 October, 2020.

Nunnally, J. C. (1978). Psychometric Theory ( $2^{\text {nd }}$ Ed.), McGraw-Hill.

Page, K. R., Castillo-Page, L., Poll-Hunter, N., Garrison, G., and Wright, S. M. (2013).

"Assessing the evolving definition of underrepresented minority and its application in academic medicine," Academic Medicine 88(1), 67-72. DOI:

10.1097/acm.0b013e318276466c

Preacher, K. J., and MacCallum, R. C. (2003). "Repairing Tom Swift's electric factor analysis machine," Understanding Statistics 2(1), 13-43. DOI:

10.1207/s15328031us0201_02

Romine, W. L., and Sadler, T. D. (2016). "Measuring changes in interest in science and technology at the college level in response to two instructional interventions," Research in Science Education 46(3), 309-327. DOI: 10.1007/s11165-014-9452-8

Romine, W., Sadler, T. D., Presley, M., and Klosterman, M. L. (2014). "Student interest in technology and science (SITS) survey: Development, validation, and use of a new instrument," International Journal of Science and Mathematics Education 12(2) 261283. DOI: 10.1007/s10763-013-9410-3

Semsar, K., Knight, J. K., Birol, G., and Smith, M. K. (2011). "The Colorado learning attitudes about science survey (CLASS) for use in biology," CBE - Life Sciences Education 10(3) 268-278. DOI: 10.1187/cbe.10-10-0133

Sissine, F. (2007, December). "Energy Independence and Security Act of 2007: A summary of major provisions," Library of Congress Washington DC Congressional Research Service.

Smith, E., and Diggans, J. (2020). "Next steps to grow the Bioeconomy," Health Security 18(4), 297-301. DOI: 10.1089/hs.2020.0012

U.S. Bureau of Labor Statistics. (2020a, January 22). Labor Force Statistics from the Current Population Survey. Available at https://www.bls.gov/cps/cpsaat18.htm

Wheeler, S. R., and Blanchard, M. R. (2019). "Contextual choices in online physics problems: Promising insights into closing the gender gap," Frontiers in Psychology, 10, 594. DOI: $10.3389 /$ fpsyg.2019.00594

Article submitted: April 27, 2021; Peer review completed: May 16, 2021; Revised version received and accepted: June 22, 2021; Published: June 25, 2021.

DOI: 10.15376/biores.16.3.5679-5693 